\title{
Erratum to: Polar amplification: is atmospheric heat transport important?
}

\author{
Vladimir A. Alexeev $\cdot$ Craig H. Jackson
}

Published online: 16 April 2013

(c) Springer-Verlag Berlin Heidelberg 2013

\section{Erratum to: Clim Dyn}

DOI 10.1007/s00382-012-1601-z

In Alexeev and Jackson (2012) the value $\gamma_{2}=2.852$ given in the caption to Fig. 2 is incorrect. The correct value that should appear is $\gamma_{2}=2.852 \times 10^{-3}$. This is the value used for all the calculations done in the article.

\section{Reference}

Alexeev VA, Jackson CH (2012) Polar amplification: is atmospheric heat transport important? Clim Dyn. doi:10.1007/s00382-0121601-z

The online version of the original article can be found under doi:10.1007/s00382-012-1601-z.

\section{A. Alexeev (ه)}

International Arctic Research Center,

University of Alaska, Fairbanks,

930 Koyukuk Drive, Fairbanks, AK 99775, USA

e-mail: valexeev@iarc.uaf.edu

C. H. Jackson

Ohio Wesleyan University,

$90 \mathrm{~S}$ Henry St,

Delaware, OH 43085, USA

e-mail: chjackso@owu.edu 